\title{
Research on Content Innovation of Distance Education in the Background of Internet
}

\section{Lei Tang}

Michigan State University, 48823, USA

Keywords: Internet, Distance education, Content innovation

\begin{abstract}
In the development process of China's Internet, the content of distance education has experienced a single text format stage, broadband network, single multimedia format stage based on audio and video, and multimedia courseware. With the rise of $3 \mathrm{G}$ and $4 \mathrm{G}$ mobile Internet, e-reading content has reached an unprecedented level of convenience, and people have gradually developed the habit of electronic reading anytime. In this context, distance education is also facing issues such as content updates and model innovation. This paper analyzes the development of distance education and the problems in the Internet background, and puts forward suggestions on the content.
\end{abstract}

\section{Teaching mode}

The teaching mode refers to the theoretical framework and activity program of the teaching structure formed under the guidance of certain teaching ideas and teaching theories to complete the teaching objectives and teaching content. It can refer to a specific teaching method, and also refers to a specific teaching procedure. In this program, school planning, courses, modules and even a class of courses can be designed. From the arrangement of classes, the creation of courses to the design of teaching materials including multimedia programs, the fundamental purpose is to promote the formation of students' learning skills and improve the learning effect. While helping students acquire knowledge, methods, values, and ways of thinking, they are also teaching them how to learn better.

With the development of information technology, the traditional learning model has undergone great changes. Throughout the history of the evolution of the teaching model, it has experienced the informatization teaching mode from face-to-face teaching to technical support from traditional face-to-face teaching to technical support. With the advent of web3.0 technology, the teaching model has injected new vitality.

The specific evolution process is shown in the figure below.

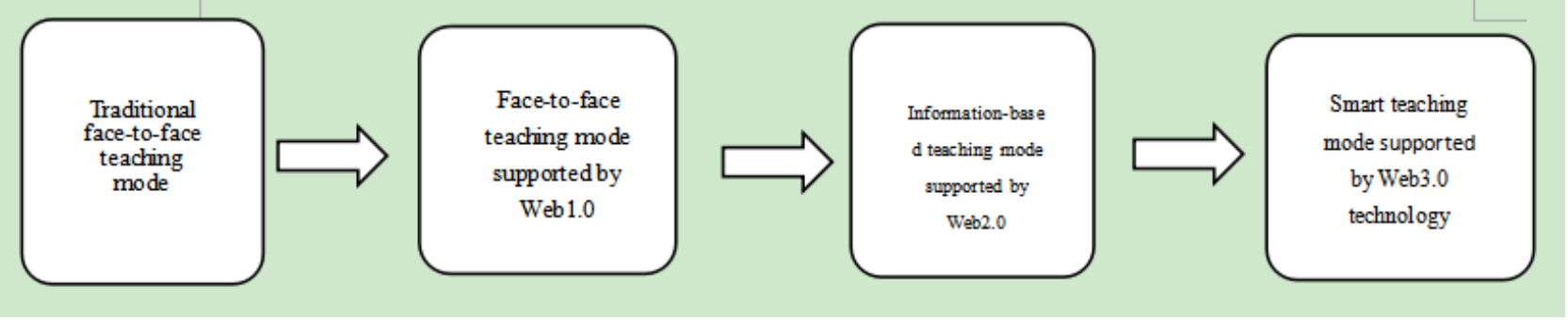

Fig 1 Teaching model evolution

Traditional face-to-face teaching: Before the Internet appeared, the teaching method was based on the teacher teaching a student to listen to the lecture. The basic form of teaching was the curriculum. The learning content was mainly based on the subject knowledge system, which was designed to help students establish a stable knowledge structure. Traditional face-to-face teaching emphasizes the unity of the pace, the student's learning path is linear, the learning method is tedious, and the students' innovative thinking is suppressed.

Information-based teaching mode of technical support: Various learning environments built by web2.0 technology provide a learning platform for learners to interact and collaborate. The teaching under the support of web2. 0 has also undergone tremendous changes, and many 
information-based teaching modes have emerged. This type of learning emphasizes the integration of knowledge, and the learning path is both linear and point-to-face. This teaching model fully respects the diversity and individual differences of students and realizes the people-oriented educational philosophy.

The smart teaching mode supported by web3.0 technology: It is characterized by networking and personalization, and provides more artificial intelligence services. The learning environment supported by web3. 0 technology can provide students with one-to-one, one-to-many, real-time and instant multi-dimensional interaction and evaluation, providing students with a comprehensive and three-dimensional interactive experience to ensure students' personalized learning. . Students can immerse themselves in the scene through virtual reality technology, and they can use mobile devices to communicate with teachers and peers.

\section{Distance education in the context of the Internet}

From the end of the last century, due to the important influence of the third industrial revolution, computer technology, communication technology, multimedia technology and microelectronic technology all developed rapidly at an unprecedented speed. We began to gradually enter the modern information society. Therefore, when the development of modern information technology continues to develop, modern distance education will emerge as the times require. It provides advanced technical support for people's lifelong learning system in the era of knowledge economy. Modern distance education is an innovative model that realizes non-face-to-face education through a variety of modern media and technologies with the advent of modern information technology. This new type of education model is embodied in the following: First, it is based on modern distance education, and on the basis of the method of face-to-face and correspondence, the teaching method of independent learning is realized. Second, it uses a variety of modern media technologies, with a variety of teaching content, close contact with the interaction between teachers and students. Third, it not only exerts its absolute superiority in teaching resources, but also provides strong technical support for the improvement of the educational quality of various educational activities. It also provides more advanced, convenient and comprehensive services for different educational objects.

Distance education is presented by network information, and its network performance is divided into three points: network resource, network interaction and network openness.

Network resource of learning mode: Due to the particularity of Internet information, distance education and traditional higher education have different performance characteristics in learning mode. He is a resource-based learning mode.

\begin{tabular}{|c|c|c|}
\hline \\
\hline & Traditional learning mode & Resource learning mode \\
\hline Learning resource types & Main textbooks Various types of & Teaching resources \\
\hline Learning organization & Class study group study & Individual learning content and focus \\
\hline $\begin{array}{l}\text { Focus on facts and } \\
\text { emphasize results }\end{array}$ & $\begin{array}{l}\text { Focus on problems and emphasize } \\
\text { the process }\end{array}$ & $\begin{array}{l}\text { Focus on problems and emphasize the } \\
\text { process }\end{array}$ \\
\hline $\begin{array}{l}\text { Ask students to get } \\
\text { information on their own }\end{array}$ & $\begin{array}{c}\text { Provide students with ready-made } \\
\text { information }\end{array}$ & $\begin{array}{l}\text { Ask students to get information on their } \\
\text { own }\end{array}$ \\
\hline Teaching evaluation & Summative evaluation & $\begin{array}{c}\text { Eacher evaluation combined with student } \\
\text { self-evaluation,Both formative and } \\
\text { summative evaluations }\end{array}$ \\
\hline $\begin{array}{l}\text { Student status Student is } \\
\text { the passive recipient of } \\
\text { information }\end{array}$ & $\begin{array}{l}\text { Students are the active acquirers, } \\
\text { processors and effective users of } \\
\text { information }\end{array}$ & $\begin{array}{l}\text { And the autonomous controller of the } \\
\text { learning process }\end{array}$ \\
\hline Teacher's role & $\begin{array}{l}\text { The teacher as a subject expert, the } \\
\text { messenger of information, the } \\
\text { controller of the memory }\end{array}$ & Learning process \\
\hline $\begin{array}{l}\text { Requirements for teacher } \\
\text { competence }\end{array}$ & Teaching ability & $\begin{array}{l}\text { Ability and ability to master advanced } \\
\text { teaching techniques }\end{array}$ \\
\hline
\end{tabular}

Fig 2 Comparison between resource-based learning mode and traditional learning mode 
As can be seen from the above table, resource-based learning emphasizes learner-centeredness and emphasizes the initiative and consciousness of student learning, which coincides with the connotation of e-learning. Secondly, resource-based learning can cultivate students' innovative thinking, gain a deep understanding of what they have learned and innovate. Finally, the learning time of resource-based learning is very flexible, and the learning effect varies from person to person.

Network Interactivity of Teaching Relationships: In the field of networked distance education, the requirements of interactivity have always been highly praised and pursued, and the requirements for the teaching structure have also increased a lot. Its characteristics include "timely response", that is, online education's feedback on non-manual issues is timely. For some basic, stylized questions, the education system should give right and wrong judgment and give an answer. "Selective" means that students should choose what they are learning based on big data. "Two-way communication" should allow students and online teachers to communicate in both directions. "Adaptability" means that the online education system should be anthropomorphic, have higher artificial intelligence, and develop different learning plans according to the characteristics of different students.

Network openness of educational structure: Network openness is the most important content in the networked nature of distance education. In the past education, due to the limitations of university entrance conditions, many quality educational resources are often in the hands of a small number of people. If you put educational resources online, you can break through the constraints of time, space and thresholds and reach the electronic terminals of everyone who has the intent to learn. The development of network has made traditional higher education power not only concentrated in the hands of the educators, but also allows learners to enter the power structure more. Students can choose among the many excellent educational resources that suit them. In a sense, such powers will be overturned and will further promote the optimization and upgrading of higher education resources.

\subsection{The evolution of the relationship between Internet +" and distance education}

Although the "Internet + " is proposed for the social, economic, industrial, agricultural and other social fields, there is no specific reference to the field of education. However, the integration of the Internet and distance education has been on the road. From the birth of the Internet to the first decade of this century, the relationship between distance education and the Internet is: distance education + Internet, that is, the Internet is only a carrier, platform or environment for distance education, which is also in line with the needs of the development of distance education. However, due to the formation and development of the "Internet + " technology ecology, the relationship between the current distance education and the Internet has changed: "Internet + distance education", the Internet is the foundation of distance education, and the development of distance education should follow the Internet. Logic and law, distance education should encourage innovative Internet thinking to meet the characteristics and requirements of the Internet technology ecosystem. The specific relationship is shown in the figure.

\subsection{The change of thinking concept of distance education under the "Internet +" perspective}

How to solve the problems in the process of distance education has always been the focus of research and exploration by distance researchers and practitioners. From the perspective of philosophical methodology, it is divided into two paths: one path is to introduce distance education continuously with new technology, and replace the defective or problematic system or platform, that is, to solve the defects of technology itself with the improvement and advancement of technology. The other path is to reflect on the nature, the reason and the state of distance education from the perspective of humanities, and try to realize the control of technology in distance education by theoretical changes, the transformation of ideas and the transformation of culture. Various obstacles and problems. These two paths have their own characteristics and deficiencies. Under the "Internet +" new technology ecological environment, we should follow the Internet spirit and laws, integrate big data thinking and subversive thinking into the process of distance education, then the technology will be invisible. Among the educational strategies, educational paths, and educational services, we will return to the educational nature of distance education to improve and improve learners' learning performance. 


\section{Innovation of distance education content under the background of the Internet}

\subsection{The main problems in current distance education}

Entertainment content still dominates, and the market is extremely lacking in appropriate distance education content. The content of distance education is extremely scarce, and students still rely on paper education content. Few students use their smartphones to learn English, but the advantages of mobile phones as a collection of functions such as text display and media playback have not been fully realized.

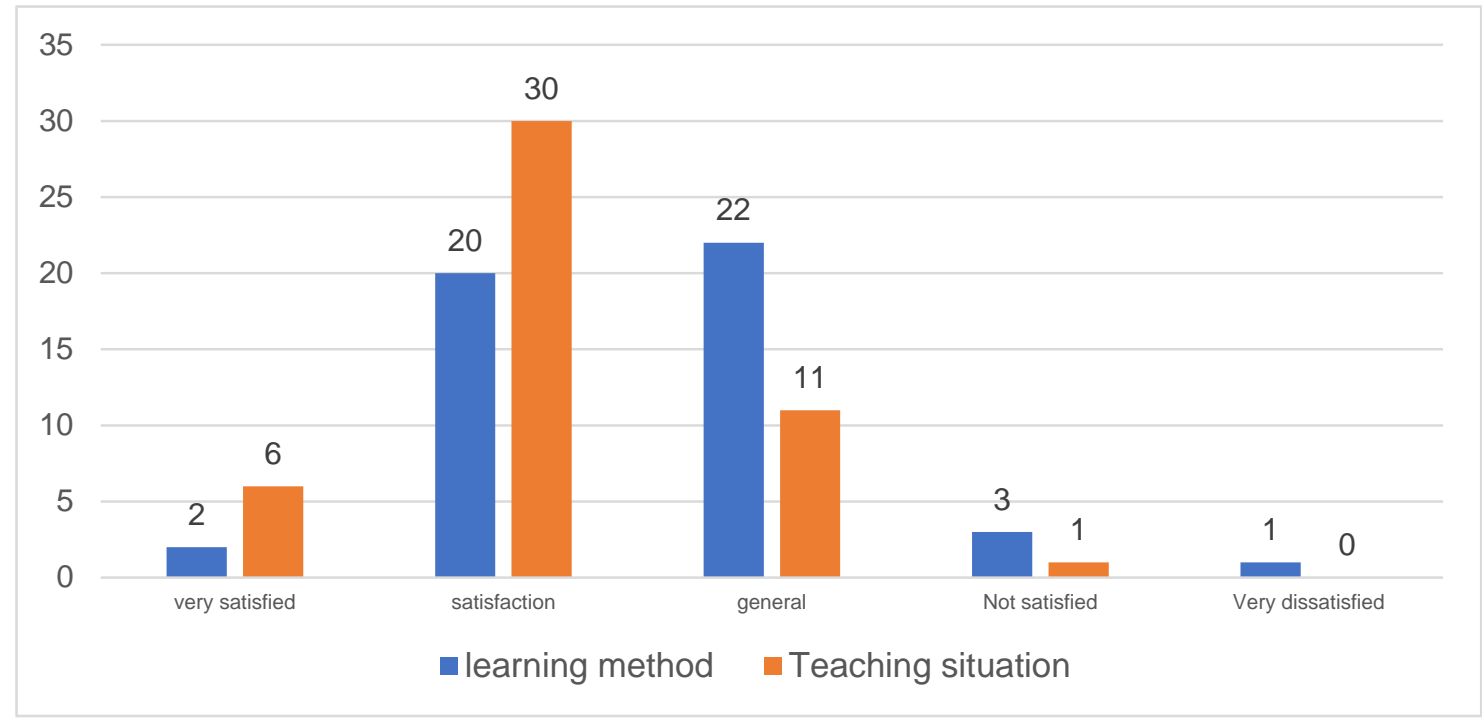

Fig 3 Course satisfaction statistics

Emphasis on the diversity and interactivity of early childhood education, but neglecting the needs of higher age students. While an assortment of apps has deepened the fun of learning for children, such interactive learning content for higher-skilled students has rarely been discovered. Instead, it is simply a picture-solving process of solving problems in mathematics, or a daunting teaching material composed of large boring texts. The interactive design of teaching content is seriously inadequate.

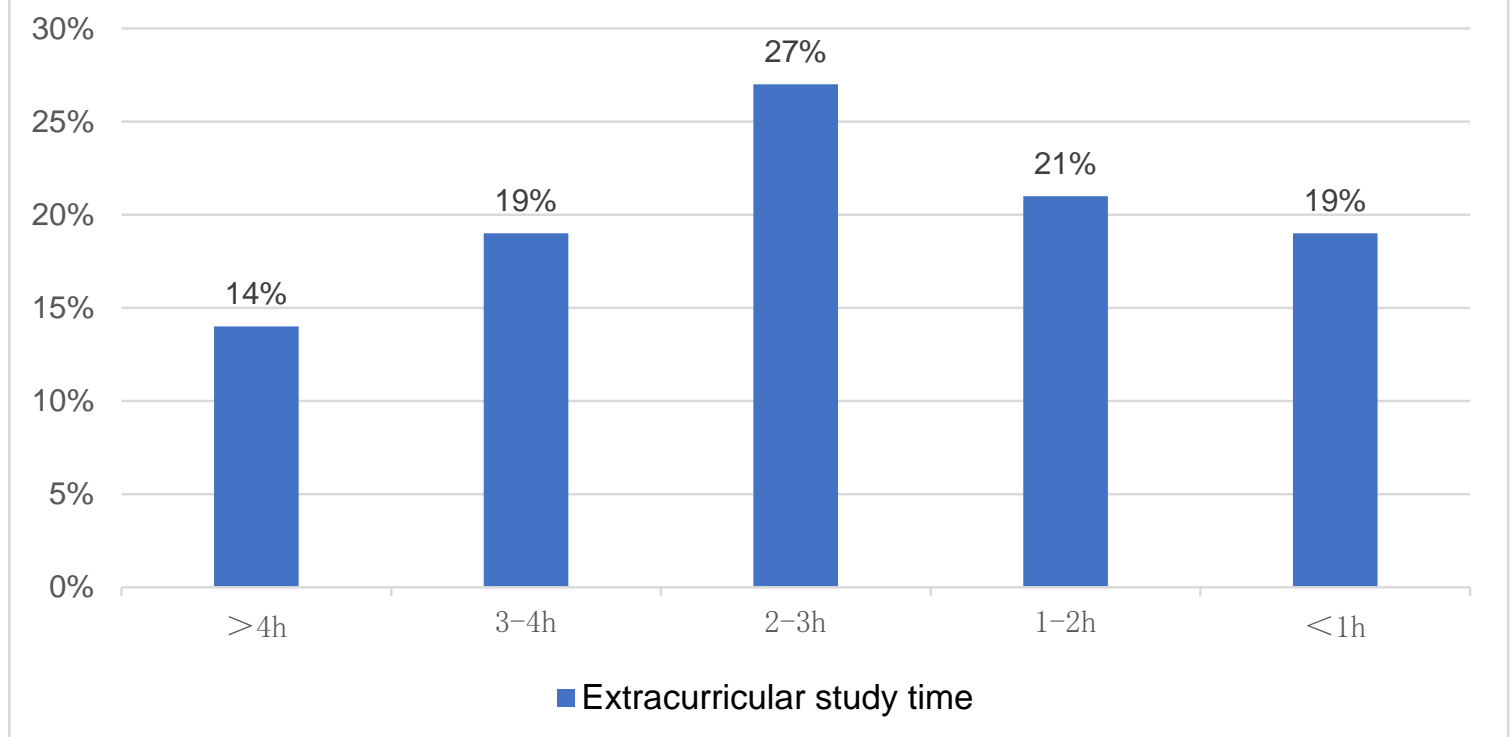

Fig 4 Extracurricular learning time statistics

Lack of systematic content planning, content layout that is prone to confusion when emphasizing content innovation. While many content providers emphasize content innovation, they ignore the path characteristics of educational content, that is, parallel and scattered content appear in large numbers, and each display unit lacks a logical order, giving people a dazzling feeling.

"Network-based personalized teaching" currently faces the following problems and needs to be 
explored and solved in practice: First, the promotion of "network-based personalized teaching" needs to be further improved. Open educators should raise their awareness of the importance of individualized teaching. Open universities must continue to deepen the reform of open education and talent training models to meet the diverse needs of learners. Second, the curriculum content design and expressions that meet the learner's individualized learning needs need to be improved. Third, the criteria and methods for process evaluation of individualized learning for learners need to be established. Fourth, the assessment and evaluation of the teaching and service quality of teachers in each branch needs to be strengthened.

\subsection{Distance Education Content Innovation Suggestions}

This paper conducts a questionnaire analysis on the distance education of a college of continuing education in a university in Guangzhou, and studies the extracurricular learning time, learning style, and satisfaction with teachers. The study found that students' extracurricular learning time is generally short, and the content of learning and the form of learning are relatively simple, especially the comparison of the needs of learning content. However, the existing distance education resources can't keep up with the learning needs, which greatly restricts the students' learning efficiency and learning quality.

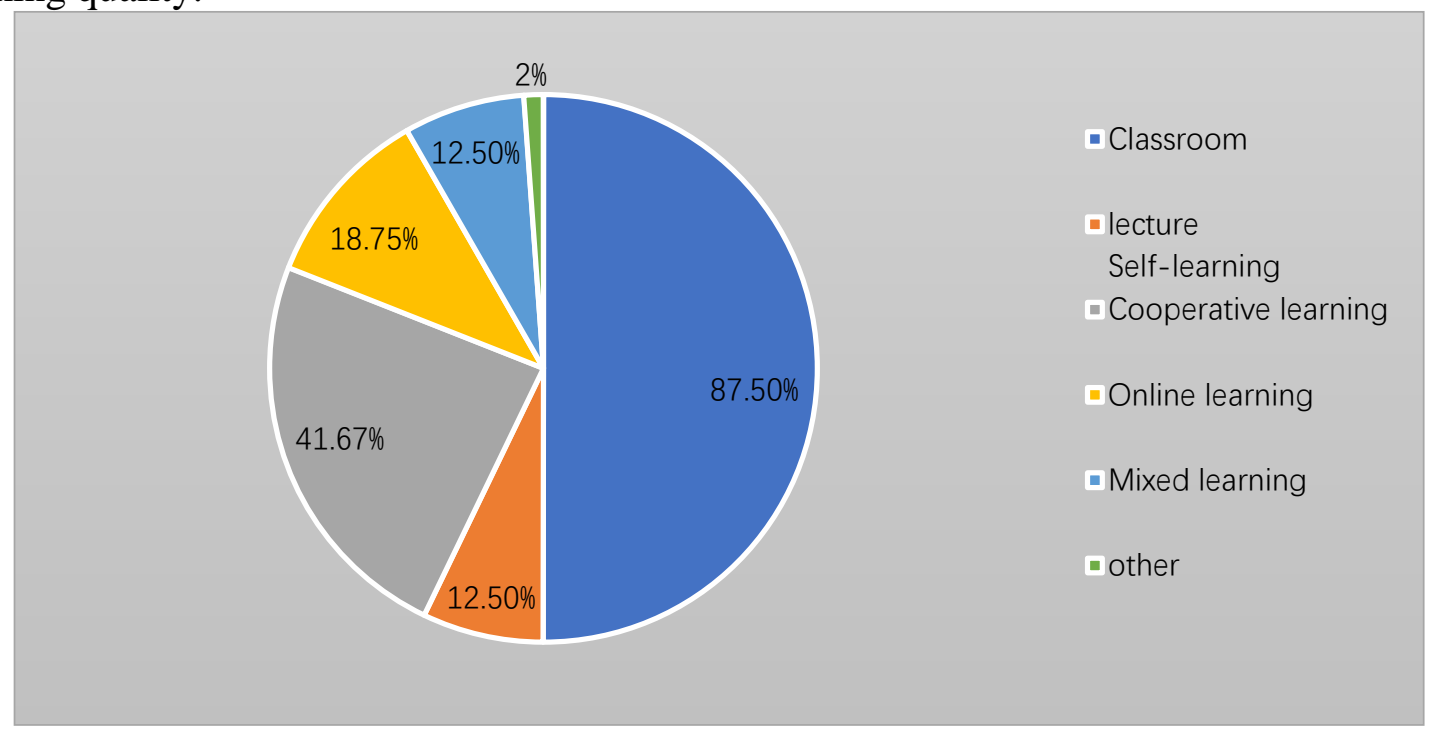

Fig 5 Learning style chart

\subsubsection{Establish a unified teaching resource platform}

With the continuous expansion of the scale of open and open education, teaching resources have become an indispensable support condition for the sustainable development of remote open education. The level of teaching resources construction has become an important guarantee for deepening teaching reform and improving teaching quality. In order to meet the needs of scholars' individualized learning of oral growth, under the unified rules, linkage and openness are realized for the learners to choose and use.

\subsubsection{Form learning support and service models}

Learners' choice of learning time and place of study makes their needs for learning support and services more urgent. To this end, the Open University should establish a unified consultation.he service organization will give full play to the role of the distance learning reception center and provide individualized services for learners. 


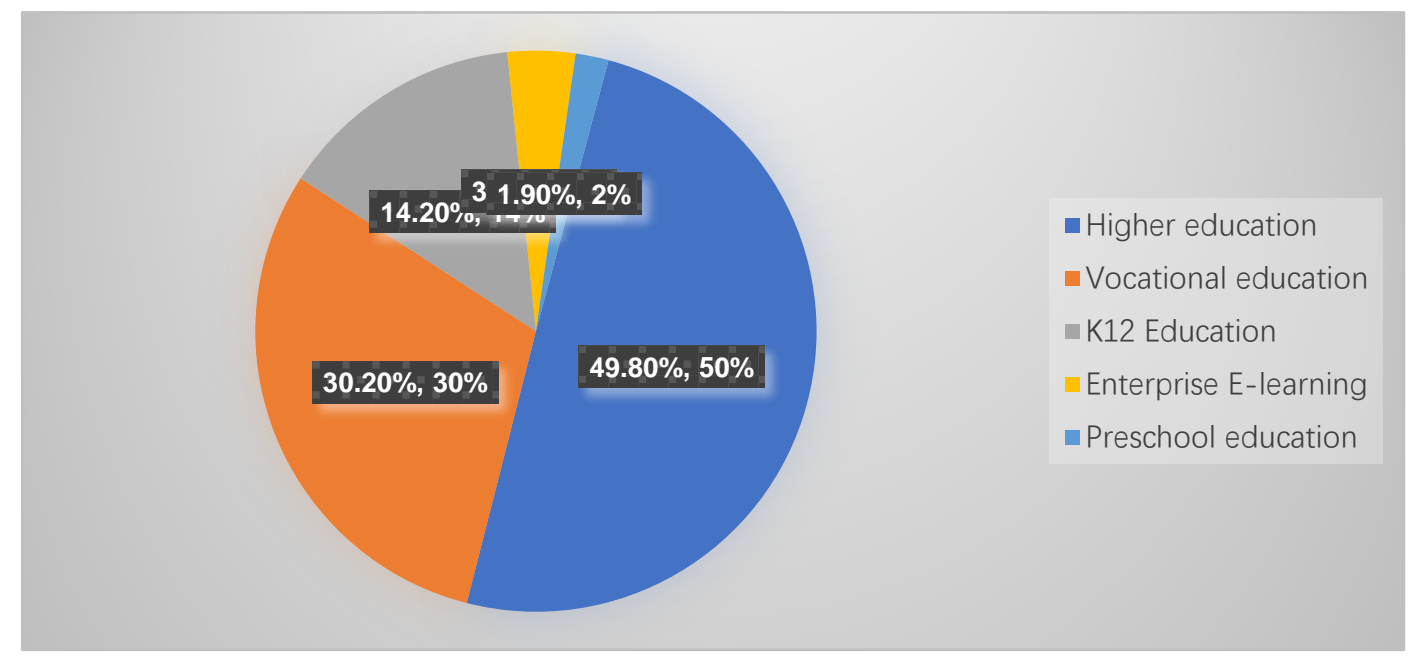

Fig 6 Comparison of different educational models

\subsubsection{Develop and build learning resources suitable for "gaming learning”}

Learning resources are best game-like, so that learners can constantly observe, experience, reflect, and comprehend in the activities. The key to the design of learning resources for "game-based learning" is that the resources themselves can detect the learner's real-time learning situation, and can provide certain clues and immediate feedback when learners solve complex problems.

\subsubsection{Develop and build learning resources suitable for "micro-learning”}

Such resources should have clear learning objectives, short content, focus on a topic, solve a problem; not emphasize systemic and academic integrity, but highlight the key content of the course

And decomposed, the relevant knowledge points are presented one by one, and fragmented learning is carried out.

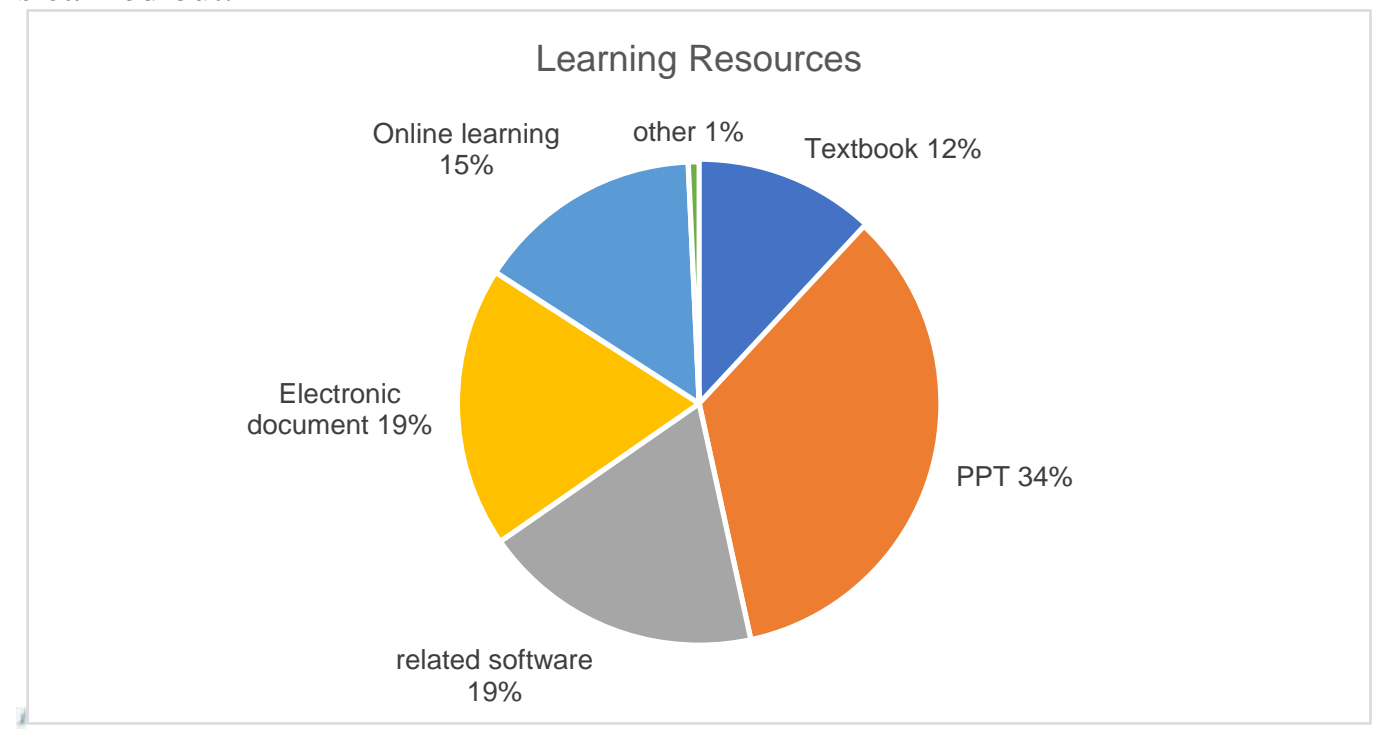

Fig 7 Learning resource chart

\subsubsection{Extend interactive educational content services}

For example, the geographical location information of the user is collected by using the GPS module of the device. Develop voice interactive content using the device's voice input capabilities. Develop video interactive content with the device's video capture capabilities. With the use of community-based communication effects and interactive functions, the solution of problems is unprecedentedly convenient, and so on, so that educational content can make revolutionary progress on such a complete technology. 


\section{References}

[1] J.N.S. Mutanyatta. Innovation in distance education learning systems: the case of the National Correspondence Institute of Tanzania, 1972-2002[J]. Open Learning: The Journal of Open, Distance and e-Learning, 2008, 23(1):57-65.

[2] Anderson T. Design-Based Research and Its Application to a Call Centre Innovation in Distance Education.[J]. Canadian Journal of Learning \& Technology, 2005, 31(2).

[3] J.N.S. Mutanyatta. "Innovation in distance education learning systems: the case of the National Correspondence Institute of Tanzania, 1972-2002." Open Learning: The Journal of Open, Distance and e-Learning23.1(2008):57-65.

[4] Malinovski T, Lazarova M, Trajkovik V. Learner-content interaction in distance learning models: students' experience while using learning management systems[J]. International Journal of Innovation in Education, 2012, Vol. 1(No. 4):362-376.

[5] Hong H. Innovation research on distance education training mode in TV University-Take Dalian TV University as an example[J]. Journal of Harbin Vocational \& Technical College, 2015. 